\title{
The Influence of Business Group Factors on the Financial Performance of Informal Micro Retail Enterprises in Nairobi.
}

\author{
Caroline Grace Wanjiku *, Patricia Chepwogen Chepkwony ${ }^{* *}$ \\ DOI: 10.29322/IJSRP.11.06.2021.p11435 \\ http://dx.doi.org/10.29322/IJSRP.11.06.2021.p11435
}

\begin{abstract}
The study focused on the informal micro retail sector in Nairobi researching on the enterprises in the Smart Duka project run by a Non-Governmental Organization and investigating the use of group participation and its effect on the financial performance of these enterprises which are located in the informal settlements of Nairobi. Prior studies have focused more on areas outside the informal sectors of Nairobi and have had limited focus on the effect of group participation on financial performance of enterprises which the current study sought to address. The financial performance and business factors of the enterprises that joined groups (treated group) were compared to financial performance and business factors of the enterprises that did not join groups (control group) in the project. The research design used a triangulation approach using an experimental and explanatory designs to study causal links investigating if there is a link between variables. Primary and secondary data from the project was used to get quantitative data collected from the sample of 116 retail enterprises in groups randomly picked using probability sampling from the project and 116 retail enterprises not in groups. Based on the results of the study, the null hypothesis of financial performance of enterprises in business groups being less or equal to that of enterprises not in business groups was accepted due to the difference between the treated and control groups being statistically insignificant despite being higher and hence ways of making this difference significant should be addressed. The managerial factors had positive insignificant effects, strategic fit factors had positive significant effects while financial factors had negative insignificant effects on financial performance of the enterprises. The study offered novelty by focusing on the most marginalized of micro enterprises- those operating in informal settlements within Kenya's capital - Nairobi while considering the effect of group networks and magnitude effect of group factors on financial performance of micro enterprises.
\end{abstract}

Index Terms- Informal sector, Group factors, Micro-enterprises, Financial performance

\section{INTRODUCTION}

$\mathrm{B}$ ackground of the Study

In Kenya, unemployment has been one of the major issues affecting the nation and stood at $7.4 \%$ in $2015 / 2016$ while the global unemployment rate was at 5.7\% in 2017 and 5.3\% in 2018 (Economic Survey, 2018) and (Economic Survey, 2019).
Economic Survey (2019) reported that the economy created 840,600 new jobs in 2018 of which $83.6 \%$ were in the informal sector. As per National Micro, Small and Medium Establishment Survey by KNBS (2016) the micro enterprises under the category of wholesale \& retail trade enterprises cover a large proportion of the informal Micro Small and Medium Enterprises, hence there is need to investigate on ways in which these enterprises can increase their financial performance for their sustainable growth to provide more employment opportunities in Kenya.

The National Micro Small and Medium Enterprises Survey by KNBS (User, 2016) categorizes Micro Small and Medium Enterprises using number of employees ; Micro are those that have 1-9 employees, Small have 10-49 employees and Medium 50-99 employees. As Chatterjee and Wehrhahn (2017) posit, most economies depend on the financial contributions of Small and Medium Enterprises with up to $95 \%$ of global enterprises being Small and Medium Enterprises with the proportion being as high as $99 \%$ in countries such as Japan. A World Bank report further highlights that up to $60 \%$ of total employment and $40 \%$ of national GPD in emerging countries is contributed by Small and Medium Enterprises (The World Bank, 2019). These support their significance in various economies while portraying the significance of the study.

Beck and Cull (2014), focusing on the situation in Africa posit that despite the high reliance of economies on small and micro-enterprises, the financial situation in the continent is by and large characterized by financial systems that are small, costly and shallow; these institutions are therefore often unable to supply much needed support for micro enterprises in the region. The resulting situation in the continent, as Brink Asah et al. (2015) observe, is the failure of up to $80 \%$ of entrepreneurial ventures. It may therefore be inferred that micro enterprises play a vital role in global economies and particularly so in Africa. However, such establishments in the continent face eminent ruin on account of a stark lack of support.

The informal sector in Kenya has been growing rapidly and is currently the highest form of employment. According to the ATKearney Global Consumer Institute (2016), the informal sector in Kenya accounts for USD 26 billion with the sector contributing to $35 \%$ of the country's GDP. As per the National Micro, Small and Medium Establishment Survey by Kenya Bureau of Statistics (2016), many Micro, Small and Medium Enterprises are undocumented enterprises and are informal while most of the Micro, Small and Medium Enterprises are micro enterprises and are operated by owners with a few or no employees. The bigger firms which are few, are owned by individuals who are highly 
educated. As per the National Micro, Small and Medium Establishment Survey by Kenya Bureau of Statistics (2016) the Micro sector makes major contributions to the economic and social sectors of the country by large scale employment across the country.

Many of the business owners adopt self-sponsored training indicating that business owners are aware of their deficiency in skills and seek training to improve their entrepreneurial skills (Bureau of Statistics, 2016). The 2016 survey further indicates that the highest concentration of Micro Small Medium Enterprises is in micro categories as majority of such enterprises are operated by their owners. It is therefore apparent that there is potential for invigorating the micro subsector through offering adequate support for such establishments.

Kamunge, Njeru \& Tirimba (2014), in their study on factors affecting the performance of micro and small enterprises located in Limuru, Kenya included such factors as; access to finance, management experience, business information access, infrastructure access, government policy and regulations. These results were congruent with the study results by Ntakobajira. Ntakobajira (n.d.) posits in the study in 2013 on SMEs in City Park Nairobi that, access to finance, business information and experience of managers need to be all made available for SMEs to realize their full potential and also recommend on having infrastructures in place to share business information with large numbers of entrepreneurs.

Maina (n.d.) in the study of 2016 on factors affecting growth of micro enterprises and small family enterprises in Nairobi central business district recommends that managers and employees of these organizations should be given training to enhance performance skills. This recommendation supports the conclusion of the study by Siekei, Wagoki and Kalio who cited financial training as an important aspect in performance and growth of SMEs. Siekei, Wagoki and Kalio (2013) in their study on funding initiatives by equity bank Kenya and on the financial training aspects provided to select SMEs in Njoro, Kenya, their findings indicate that businesses that participated in the bookkeeping training fared better than those that did not.

Mungai \& Ogot (2017) in their study in Muranga, Kenya conclude that micro enterprises use diverse competitive business strategies and pointed out the ones that dominate are; the value chain approaches and horizontal networks and linkages, which improve performance. Micro enterprise participation in value chains involve vertical linkages both forward and backward with larger enterprises while horizontal linkages are informal and formal networks with enterprises of similar size either directly or through associations and organizations. However, they do mention that these alternative strategies were not covered in their study and were an opportunity of further research.

This study centres on the provision of support through business group participation by micro enterprises operating in informal settlements in Nairobi. The study focused on the informal micro retail sector in Nairobi researching on enterprises in the Smart Duka project run by a Non-Governmental Organization and investigated the use of business group participation factors and their effect on the financial performance of these enterprises. In the project, various formal practices are used, which include training, merchandizing, record keeping, customer service, use of technology, supplier management, loan accessibility and group associations. The groups formed have been used to access various facilities in the market including supplier group discounts, ease of delivery of merchandize to the enterprises, accessibility to loans and better negotiating power. The three main aspects and factors of business group participation include - financial, managerial, and strategic-fit interventions. This study therefore sought to fill the gap in research by providing empirical evidence of the impact of group participation in the financial performance on micro enterprises while considering various factors under the financial, managerial and strategic fit categories. The study further offered novelty by focusing on the most marginalized of micro enterprises- those operating in informal settlements within Kenya's capital - Nairobi while considering the effect of group networks and magnitude effect of group factors on financial performance of micro enterprises. Prior studies have put their focus more on areas outside the informal sectors of Nairobi and limited focus on the effect of group participation has been accorded in prior studies which the current study seeks to address.

\subsection{Statement of the Problem}

Previous literature has examined factors such as access to finance, business information access, infrastructure, training, business linkages and government policy as variables that would influence financial performance of micro-retail enterprises however these do not offer alternative strategies that are geared towards financial performance of the microretail enterprises. Scant literature examines the relationship between business group participation factors and financial performance while considering various factors under the financial, managerial and strategic fit categories which have been highlighted in various studies as important factors in the financial performance of enterprises. The study offers novelty by focusing on the most marginalized of micro enterprises- those operating in informal settlements within Kenya's capital - Nairobi while considering the effect of group networks and effect of group factors on financial performance of micro enterprises.

\subsection{Research Objectives}

\subsubsection{General Objective}

The general objective of the study is to establish the relationship between business group factors deemed effectful on micro enterprise financial performance measured by sales growth. The specific objectives are highlighted below.

\subsubsection{Specific Objectives}

1. To assess the effect of financial factors in business groups on the financial performance of informal micro retail enterprises in the Smart Duka project.

2. To assess the effect of managerial factors in business groups on the financial performance of informal micro retail enterprises in the Smart Duka project.

3. To assess the effect of group strategic-fit factors in business groups on the financial performance of informal micro retail enterprises in Smart Duka project.

\subsubsection{Research Questions}

1. What is the effect of financial factors in business groups on the financial performance of informal micro retail enterprises in Smart Duka project? 
2. What is the effect of managerial factors in business groups on the financial performance of informal micro retail enterprises in Smart Duka project?

3. What is the effect of strategic fit factors in business groups on the financial performance of informal micro retail enterprises in Smart Duka project?

\section{LITERATURE REVIEW}

\section{Financial factors and financial performance of Informal Micro Enterprises}

Tinajero \& Lopez-Acevedo (2010) found in their study of SME programs in Colombia, Peru, Mexico and Chile, that participation in SME programs results in increased sales across the various countries. The study was motivated by the fact that SMEs make up a high proportion of enterprises and workforce but perform poorly in comparison to larger firms due to the constraints they face; lack of finance, management issues, lack of skilled workers, in economies of scale, poor technology, lack of information and markets, bureaucratic processes of start-up, operations and growth. Programs are put in place for SMEs for skills development, training on management, upgrade of technology, improve productivity and quality and for network formation. This finding was similar to Kamunge, Njeru \& Tirimba (2014) in their study in Muranga who cited business information and infrastructure access as important factors in the financial performance of micro enterprises.

Kodongo \& Kendi (2013) from their study results conclude that among micro finance institution clients, a group lending program is more effective than individual lending program to reduce the risk of default. This implies a collaborative lending approach centring on the grouping of micro enterprises to allow for financial competencies through extension of loans to groups. This approach of leveraging groups to allow for allocation of resources is in keeping with the RVB and SET theory. However, they do also conclude in their study that Kenyan microfinance institutions prefer individual lending which does not meet the borrowers' financials needs and is wasteful (Kodongo \& Kendi, 2013).

Beck \& Cull (2014) state that more than $95 \%$ of enterprises are under micro, small or medium sized categories while more than half the population of employees work in companies with less than 100 employees in the low and lower middle income countries as per finding by (Ayyagari, Demirguc-Kunt and Maksimovic 2011). Beck \& Cull (2014), posit these enterprises experience operational and growth obstacles such as lack of access to financial services most notably, lending services as is also highlighted by (Tinajero \& Lopez-Acevedo, 2010). For these smaller enterprises, the following are proposed; leasing is preferable due to lack of collateral requirements as the option provides the asset instead of financial resources, factoring (the discounting of sales receivables), financial innovations, segmenting the enterprises as per profiles, financial needs and equity finance.

Beck \& Cull (2014) also posit that growth of firms is due to individuals who have different levels of management skills, education and motivation and hence understanding the effect of social networks and education is important for success in entrepreneurship, which was also also supported by Kamunge, Njeru \& Tirimba (2014) who highlighted management experience as an important factor for financial performance. The authors, through a regression model, point to similarity in financing determinants across regions in that such factors as age of enterprise, sector and firm size play a pivotal role in determining the financing approaches applied by companies. However, the authors posit that the financial situation in Africa is characterized by financial systems that are small, shallow and costly and often limited in reach hence highlighting the need for innovation in financing approaches and particularly so for micro enterprises.

According to statistics presented in contrasting financing by company size, it was apparent that companies with less than 20 employees (micro enterprises) were significantly underfunded across all loan categorizations. This finding in light of the RBV theory would therefore imply that a collaborative lending approach centring on the grouping of micro enterprises can be leveraged to allow for financial competencies through extension of loans to groups with less than 20 employees which is supported by SET theory. Such an innovative approach would navigate the highlighted challenge of inaccessible financing for the segment. The recommendation by Beck \& Cull (2014) on innovation in financing approaches was in line with the recommendation by Chatterjee \& Wehrhahn (2017) to create innovative products that leverage on pooling of resources.

Kadocsa \& Francsovics (2011) in their study of SMEs in Hungary conclude that after Hungary's accession to the European Union, the small businesses did not take advantage of the European Union new markets and opportunities due to lack of information. The eventual situation therefore, was that organizations were operating in a promising market yet did not leverage the tools that were at their disposal. The authors highlight networking among enterprises as a possible approach towards remedying the situation in the country. The study therefore indicates that economic competencies can be developed through partnership aimed at identifying opportunities in the broader market. Mungai \& Ogot (2017) in their study in Muranga also did highlight networks and linkages as important factors for financial performance.

Kadocsa \& Francsovics (2011) in their study concluded that two thirds of SMEs consider the economy as stagnating or slightly improving and mainly sell in the retail market and have moderate development and mostly use their own resources. The study further found that a reliable monetary policy had the most impact on business operation among economic policy factors while for the micro economic factors the important ones were cost management, marketing, trade, financing, technical development and production. Chatterjee and Wehrhahn (2015) provide telling statistics on the prominence of SMEs to the global economy - up to $95 \%$ of enterprises are SMEs; these account for up to $90 \%$ of private sector employment. The proportion of SMEs differs by country with countries such as Japan posting up to $99 \%$ of SME representation. Further highlighting the prominence of the microSME sector, the authors point to a World Bank study indicating that up to $70 \%$ of the MSMEs are operating in the informal sector and are mainly defined as micro enterprises. However, despite the high proportion in the global economy such enterprises remain heavily underfunded. 
Creation of micro insurer solutions may be the most effective way of addressing risk among small enterprises in Africa (Sampson Ukpong, Acha, \& Sampson 2019). In a study conducted in Nigeria, the authors surmise that the challenge of inaccessibility of funds among small enterprises results in the inability of firms to meet the threshold requirements for mainstream insurance. Such enterprises are therefore, in light of lack of options, left uninsured. To navigate this challenge, the author after assessing 6 possible possibilities, conclude that the formation of cooperatives would serve to create the common pool of resources that can allow for the insurance of groups or firms. The authors further observed that seeking insurance through cooperatives as opposed to community-based schemes offered the advantage of formality; where as in the former cooperatives interact with mainstream insurance companies, community-based schemes were less formally oriented and therefore, did not require engagement with mainstream insurance companies that typically serve a regulatory function. Relating this finding with the previous study by Chatterjee \& Wehrhahn (2017), it is evident that financial institutions that appreciate the predominance of small enterprises in the economy of developing countries can create innovative solutions that allow for the advancement of the much needed assistance while sufficiently shielding the funders from defaulters.

Siekei, Wagoki and Kalio (2013) provide a case study of the performance of 82 farms in Njoro in Kenya. The study centres on funding initiatives by equity bank Kenya. Specifically, the authors focus on the financial training aspects provided to select SMEs. The study seeks to assess whether such competences as bookkeeping present a significant impact on the financial performance of firms. Findings indicate that indeed businesses that opted to participate in the training that was offered to the group, fared better than those that did not gain the training provided by the bank. This finding points to the training aspect involved in group initiatives aimed at achieving financial performance among small and medium sized enterprises. It is therefore evident that among the benefits of group participation is the ease of training, training that has been shown to have a financial impact on the performance of involved firms. This study was congruent to the one by Maina (n.d.) regarding training having a significant impact on financial performance.

Maina (n.d.) in the study of 2016 on factors affecting growth of micro enterprises and small family enterprises in Nairobi central business district recommends that managers and employees of these organizations should be given training to enhance performance skills. This recommendation supports the conclusion of the study by Siekei, Wagoki and Kalio (2013) who cited financial training as an important aspect in performance and growth of SMEs.

\section{Managerial factors and financial performance of Informal Micro enterprises}

Whereas financial factors present as the most telling limiting issue in the performance of small firms, managerial factors also play a significant role, most SMEs do not have management solutions that are cost effective and hence cannot compete with larger firms (Abor \& Quartey, 2010). Jeppesen (2005) as the author observed, weak financial institutions and wanting regulations, as applicable in different industries, result in peculiar challenges among small enterprises operating in the continent. Managerial competencies therefore present as fundamental determinants of the financial progress of firms. This is similar to the study of Ntakobajira (n.d.) and Kamunge, Njeru \& Tirimba (2014) who concluded that experience of managers is an important factor affecting the performance of enterprises.

Atristain-su (2018) in a study of managerial practices in small and medium enterprises in Mexico, highlights that the institutions are plagued by a variety of managerial issues. Among the most noteworthy shortcomings are in the planning, decision making, delegation, and communication aspects of the companies. The author points to family business ownership as among the main reasons behind the lack of professionalism within most of the institutions considered in the study. The author further points to the reliance on intuition in management of firms as a possible reason behind the lack of internal controls within considered institutions. Essentially, interactions between family members in their business setting makes creation of controls and measures in a professional environment a daunting task. The author further recommends that managers of the various institutions focus on aligning strategic goals with managerial practices so as to achieve intended financial outcomes. This is similar with the study by Asah \& Olufunso (2015) who highlight planning as part of the management skills that increase performance of enterprises.

Kamunge, Njeru \& Tirimba (2014), in their study on factors affecting the performance of micro and small enterprises located in Limuru, Kenya included factors such as; infrastructure access, government policy and regulations.

Solly (2016) in an assessment of the various reasons behind the failure of small enterprises in South Africa, highlights that managerial factors play a significant role in determining the success or lack thereof, of businesses. Employing a qualitative approach involving the use of interviews, the author posits that such factors as lack of understanding of approaches to managing resources present as a main hindrance to entrepreneurs seeking to set up shop without prior experience. The author proposes a networking approach whereby seasoned entrepreneurs can use their experience to equip new business owners with the requisite skills to ensure efficient management of resources. The author further proposes consultations with managerial experts who would highlight specific areas of failures thereby allowing the affected to better navigate the perils of setting up new businesses. This approach, as was the case with the previous, emphasises the validity of the SET as such interventions centre on the idea of reciprocity in the exchange of valuable information. The recommendation by Solly (2016) on use of experienced entrepreneurs is similar to the finding of the study by Ntakobajira (n.d.) and Kamunge, Njeru \& Tirimba (2014) who highlight that managerial experience is an important factor of enterprise performance.

Asah, Olufunso, et al.(2015) in an evaluation of the significance of managerial skills in assessing the performance of firms conclude that managerial factors, alongside personal value and motivation, presented as antecedents of favourable economic performance. The author conceptualized managerial skills as involving such aspects as financial management skills, strategic planning, and human resource management concluding that managers who showed a high competence in such aspects were 
likely to steer their organizations towards improved financial performance. The inference from this finding is that micro enterprise managers involved in the exchange of managerial insights would gain in entrepreneurial management competencies thus resulting in the gaining of competitive advantage in the market within which they operate. In line with this is imperative to study the effect that managerial factors have on micro enterprises to enable improve their performance. This study is in line with Atristain-su (2018) who highlights lack of planning as part of the managerial issues experienced by enterprises in Mexico.

Kamunge, Njeru \& Tirimba (2014), in their study on factors affecting the performance of micro and small enterprises located in Limuru, Kenya included; management experience, business information access and infrastructure access. These results were congruent with the study results by Ntakobajira (n.d.). Ntakobajira (n.d.) posits in the study in 2013 on SMEs in City Park Nairobi that, business information and experience of managers need to be all made available for SMEs to realize their full potential and also recommend on having infrastructures in place to share business information with large numbers of entrepreneurs.

\section{Strategic-fit factors and financial performance of Informal Micro enterprises}

The essence of strategic fit factors as applicable to micro enterprises is the notion that identifying points of synergy between institutions operating in the same market environment would allow for the gaining of competitive advantage. This premise stems from the RBV theory. Kibry and Kaiser (2003) postulate that joint ventures, among other competencies, allow for the common sourcing of raw materials by SMEs. Through this approach, such small enterprises are able to leverage the economies of scale to allow for lower payments and in most cases efficiency gains in the process of sourcing for raw materials. This reduction in costs and increasing efficiency stems from the fact that suppliers are better able to deliver products and services in bulk as opposed to individuals as they cut costs through, for instance, decreased travel payments when supplying bulky goods. The practical application of this strategic fit factor in the local context would involve communal ordering of products and services from wholesalers to retail establishments involved in a group partnership. This finding by Kibry and Kaiser (2003) is similar to the proposal by Mungai \& Ogot (2017) on use of vertical and horizontal linkages or networks and value chains to improve performance of enterprises.

Hoffmann \& Schlosser (2001) in a study involving 164 Australian companies operating in the SME space observed that strategic alliances are gaining increasing popularity. This is because companies are able to access competencies that would otherwise not be available to them except for partnership with other like-minded firms that offer abilities that are not inherently available in their respective companies. In assessing the various determinants of strategic alliances, the authors point out that factors such as trust predicted the success or lack thereof of partnership endeavours. However, other more technical factors such as the nature of the fit between the enterprises play a significant role in determining the success of partnerships. The authors further posit that establishing the rights and duties of each of the parties involved in partnerships and the outlining of the processes in terms of engagement allow for the streamlining of the interaction between enterprises seeking to achieve the common goal of profit making. This study therefore highlights the nuance involved in achieving effective partnership between firms and supports the tenets of the SET theory as put up by Cropanzano \& Mitchell (2005) of interactions and obligations which are under the rules of exchange.

Pindado \& Sánchez (2018) opine that the resources capabilities in the context of the market with which organisations operate have a significant effect on the growth curve of new enterprises. Firms that have substantial internal resources and operate in markets characterised by low competition are likely to achieve faster growth than their counterparts with limited resources. This finding therefore indicates that limitation in resources predicates the need for the seeking out of strategic fits as companies with few resources strive to find a competitive advantage. The authors further highlight the pivotal role of competitive forces within markets; as the level of competition increases the importance of vast internal resources also increases with companies with few resources being at the forefront in experiencing the strains of highly competitive industries. It therefore may be inferred that companies should seek good strategic fit options if they anticipate harsh financial conditions and especially so if operating in highly competitive environments. The level of competition in the developing countries would be considered high given the large population of enterprises especially in the micro retail category as supported by the MSME survey (2016) done by the KNBS, hence use of strategic partnerships would assist the micro enterprises leverage from the advantages the partnerships would offer.

Mashal (2018), in a study focused on non-financial factors affecting small and medium enterprises in Jordan, observes that different businesses faced similar challenges. Among the notable of these challenges, a factor highlighted in the foregoing study, is the impact of competition. Another noteworthy observation was that the government policies in place played a significant role in determining the profitability of enterprises. The inference from this study therefore is that where such factors as competition present as challenges to collaboration, the mutual challenges facing industries should serve to spur strategic partnerships in their bid to ensure survival. Efforts towards mutual training and innovation play the role of improving the financial position of involved entities. This is supported by the study by Pindado \& Sánchez (2018) who highlighted that firms operating in markets characterized by low competition achieve faster growth while those with limited resources seek strategic fits to get a competitive advantage.

Mungai and Ogot (2017) in their study in Muranga conclude that micro enterprises use diverse competitive business strategies and pointed out the ones that dominate are; the value chain approaches and horizontal networks and linkages, which improve performance. Micro enterprise participation in value chains involve vertical linkages both forward and backward with larger enterprises while horizontal linkages are informal and formal networks with enterprises of similar size either directly or through associations and organizations. However, they do mention that these alternative strategies that had shown support towards performance improvement were not covered under the activity 
based competitive business strategy typologies by Porter and in their study and were an opportunity of further research. This study by Mungai and Ogot (2017) does support various aforementioned studies under this section of strategic fit factors that highlight the various advantages of synergies and networking such as those by Kibry and Kaiser (2003) and Pindado \& Sánchez (2018).

\section{Financial performance of Informal Micro enterprises}

Financial performance of the informal micro enterprises which was the independent variable was measured by sales growth, profit growth, inventory growth and growth in cash float. The use of these measures as the dependent variable was considered as appropriate due to the information available to the micro enterprises. Bookkeeping is a challenge to most of the enterprises due to the high granularity product levels they use hence a relative measure of growth was the form of information that was available from the micro enterprises rather than absolute sales figures over the years which were not available. Questions in relation to the dependent variable to supplement this that were included were on; sales growth, inventory growth, profit growth and cash float growth.

Isaksson \& Seifert (2014) conclude that managing of inventories gives businesses competitive advantages which results in better financial performance. This was in line with the study by Caroline (n.d.) in 2017 who concluded that in cases where there is a unit of inventory turnover growth this would lead to increase in turnover of inventory and that inventory turnover is one of the variables that affect financial performance. Hence use of inventory growth as a subfactor of financial performance was used in this study.

\section{Research Gaps}

Atristain-su (2018) suggested to have further studies on the effect of managerial practises on internal controls within family businesses to determine best performance strategies and for continuity. Thus, this study accesses the impact of managerial factors on financial performance of micro enterprises. Kirby \& Kaiser (2003) stated that there were many proponents of the strategy of joint ventures to enable SMEs with limited resources and knowledge to enter international markets yet few have focused on joint venturing activities of SMEs. In this study, partnerships as a means of joint ventures and group associations were assessed in terms of their impact on performance on micro enterprises.

Kamunge, Njeru \& Tirimba (2014), in their study on factors affecting the performance of micro and small enterprises located in Limuru, Kenya included such factors as; access to finance, management experience, business information access, infrastructure access, government policy and regulations. These results were congruent with the study results by Ntakobajira (n.d.). Ntakobajira (n.d.) posits in the study in 2013 on SMEs in City Park Nairobi that, access to finance, business information and experience of managers need to be all made available for SMEs to realize their full potential and also recommend on having infrastructures in place to share business information with large numbers of entrepreneurs. These studies focussed on micro and small enterprises in Limuru and small and medium enterprises in City Park hence there is need to study the micro enterprises especially in the informal settlements of Nairobi and establish the effect of these factors on the financial performance of these enterprises.

Maina (n.d.) in the study of 2016 on factors affecting growth of micro enterprises and small family enterprises in Nairobi central business district recommends that managers and employees of these organizations should be given training to enhance performance skills. This recommendation supports the conclusion of the study by Siekei, Wagoki and Kalio (2013) who cited financial training as an important aspect in performance and growth of SMEs. Siekei, Wagoki and Kalio (2013) in their study in Njoro on funding initiatives by equity bank Kenya and on the financial training aspects provided to select SMEs. Their findings indicate that businesses that participated in the bookkeeping training fared better than those that did not. These studies were focussed on the Nairobi central business district and Njoro areas hence there is need for the study of micro enterprises in the informal settlements of Nairobi and how such factors affect the performance of these enterprises which this study focuses on.

Mungai \& Ogot (2017) in their study in Muranga conclude that micro enterprises use diverse competitive business strategies and pointed out the ones that dominate are; the value chain approaches and horizontal networks and linkages, which improve performance. Micro enterprise participation in value chains involve vertical linkages both forward and backward with larger enterprises while horizontal linkages are informal and formal networks with enterprises of similar size either directly or through associations and organizations. However, they do mention that these alternative strategies were not covered in their study and were an opportunity of further research, which this study delves into.

This study therefore seeks to fill the gap in research by providing empirical evidence of the effect of group participation in the financial performance on micro enterprises while considering various factors under the financial, managerial and strategic fit categories. The study further offers novelty by focusing on the most marginalized of micro enterprises- those operating in informal settlements within Kenya's capital - Nairobi while considering the effect of group networks and significance effect of factors in business groups on financial performance of micro enterprises.

\section{Conceptual Framework}

In the study the dependent variable is the financial performance of the informal micro enterprises, which is measured by sales growth. The construct is deemed the dependent variable as the main aim of group interventions as to optimize the performance of participating firms. The independent variables are the financial, managerial and strategic fit factors in business groups; these entail the main means through which business interventions, through group participation, were effected. 


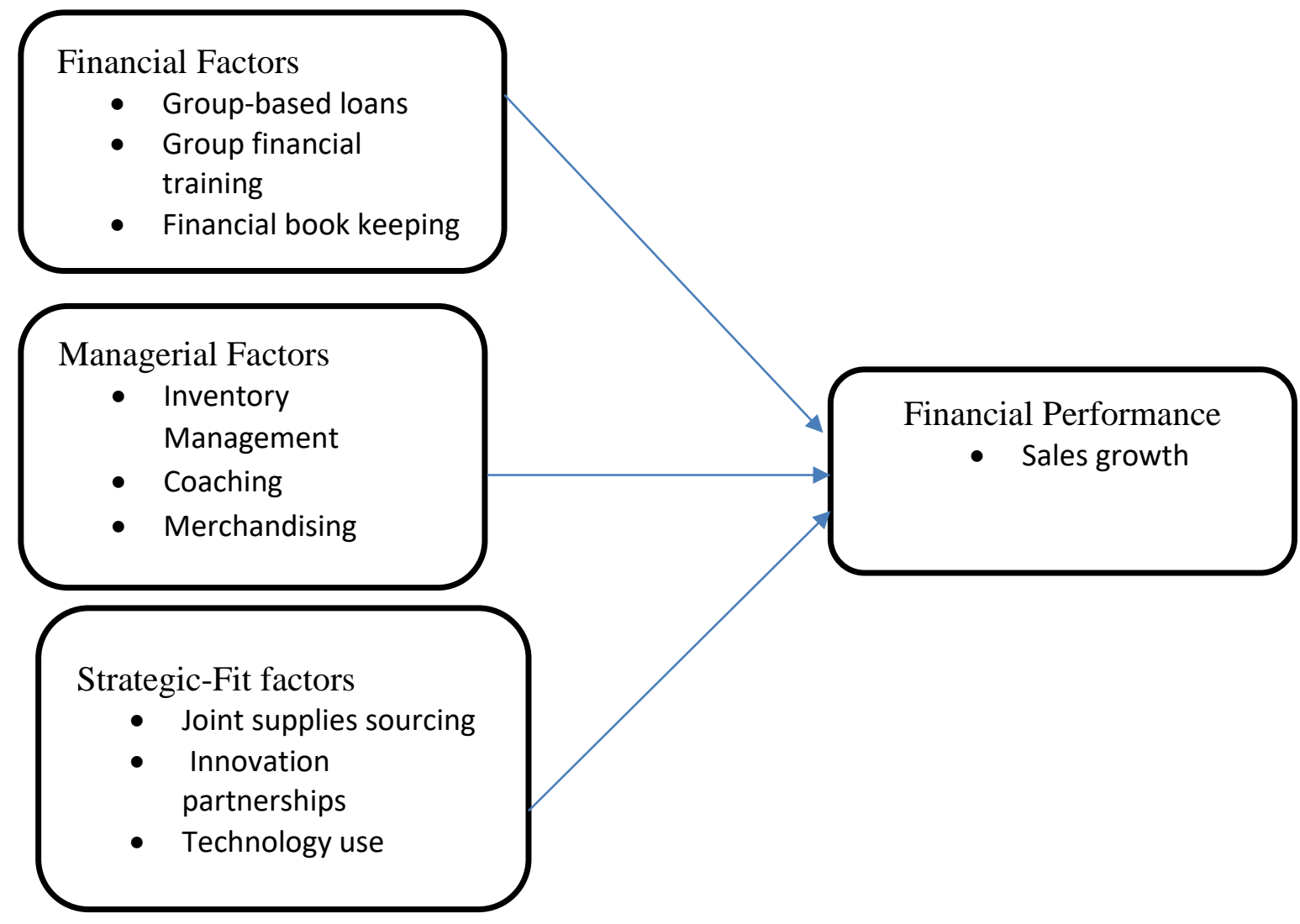

Figure 1: Conceptual framework

\section{MEthodology}

\subsection{Research Design}

The research design used a triangulation approach using an experimental and explanatory designs to study causal links investigating if there is a link between variables. The study is based on an explanatory approach, which Saunders et al. (2009) describe as a study that establishes relationships between variables, it studies a situation or problem in order to explain the relationships between variables. The study was based on an experimental design having a treated group (enterprises in business groups) and a control group (enterprises not in business groups) and also had an explanatory purpose to explain the causal relationship between business group factors (financial, managerial and strategic-fit factors) and financial performance of the enterprises.

\subsection{Population and Sampling}

The study focused on a project run by a Non-Governmental Organization that dealt with informal micro retail enterprises in the informal sectors of Nairobi. The enterprises in the project were in informal settlements of Nairobi including Githurai, Kayole, Mwiki, Kangemi, Kawangware, Huruma, Mathare, Umoja, Pipeline and Dandora. The main aim of the project was to assist grow and equip the informal retail micro enterprises.

The population of the informal micro retail enterprises in the project was 874 from the informal micro enterprises that were onboarded to the project in various cohorts with the initial baseline selection being Dec 2015 and the endline in June 2018 (Smart Duka,2019). The sampling process was quantitative and was done using probability sampling and using simple random sampling from the different areas where the project was being carried out in the informal settlements in Nairobi, Kenya. The sample was picked putting into consideration time and cost constraints. The sampling unit was the micro enterprise while the sample element was the owner of the enterprises or the main manager of the enterprises. Owners and managers of micro enterprises not in the Smart Duka Project were not eligible to take part in this study.

The basis of the sample size determination was the 'standard formula':

$n=2\left(\mathrm{Z} \alpha+\mathrm{Z}_{1-\beta}\right)^{2} \sigma^{2} /\left(\Delta^{2}\right)$

where $n$ was the appropriate sample size,

$Z \alpha$ was a constant set according to the accepted $\alpha$ error: $\alpha=10 \%$ $Z \alpha=1.28 ; Z_{1-\beta}$ dependent on the desired statistical power of the test: the study used $80 \%$ power, conventionally deemed reasonable, yielding $Z_{1-\beta}=0.8416$ Kadam \& Bhalerao (2010), $\Delta$ is the expected difference in the effect of the two groups (treated and control group) - approximately 0.07 ; and $\sigma$, the standard deviation. variability of the population is approximately 0.25 , both from the (Drexler et al., 2014).

Thus, the optimal sample size for the study was calculated as:

$$
\begin{aligned}
& n *=2\left(Z_{\alpha}+Z_{1-\beta}\right)^{2} \sigma^{2} /\left(\Delta^{2}\right)+1(1) \\
& ; n *=2(1.28+0.8416)^{2} 0.25^{2} /\left(0.07^{2}\right)+1=116
\end{aligned}
$$


Table 3.1: Sample breakdown

\begin{tabular}{lll}
\hline Description & $\begin{array}{l}\text { Sample } \\
\text { Number }\end{array}$ & $\begin{array}{l}\text { Retailer } \\
\text { Population }\end{array}$ \\
\hline $\begin{array}{l}\text { Treated group: Number of } \\
\text { informal micro enterprises }\end{array}$ & & \\
onboarded in business & \\
groups on Smart Duka & \\
Project as at Jun 2018 & \\
$\begin{array}{l}\text { Control group: Informal } 116 \\
\text { enterprises not in business } \\
\text { groups on Smart Duka }\end{array}$ & \\
Project & & \\
Total & 232 & 874 \\
\hline
\end{tabular}

\section{Data Collection Methods}

Primary and secondary data from the project was used to get quantitative data collected from the sample of 116 retail enterprises in groups randomly picked using probability sampling from the project and 116 retail enterprises not in groups. The secondary data was obtained from the Non-governmental organization that has the records for different cohorts both at the baseline as from December 2015 and end line in June 2018. Primary data was directly collected from the micro retail enterprises randomly selected by use of a questionnaire and with the aid of research assistants. The closed type questionnaires that were used were structured on the specific objectives of the study using Likert scale for rating the questions hence ordinal data for the dependent and independent variables obtained.

\subsection{Data Analysis}

Data was analyzed using quantitative analysis methods using ordinal regression modelling and diagnostic, descriptive and inferential statistics obtained as the data was quantitative in nature and hence findings were inferred for the whole population. Statistical Package for the Social Sciences (SPSS) was used for the analysis. Demographic summary statistics using Mann Whitney $U$ tests of nonparametric data for comparison of two independent groups were done. Statistical assumptions/Diagnostic tests were done for Test of Normality (Kolmogorov-Smirnov (KS) and Shapiro-Wilk tests), Homogeneity, Multi collinearity (VIF), Auto correlation (Durbin Watson), and Tests of Parallel lines/proportional odds. Descriptive analysis was done on the 3 business factors (financial, managerial and strategic fit) and financial performance using Mann Whitney $U$ tests of nonparametric data for comparison of two independent groups. Inferential analysis was done using- Spearman Correlation Coefficient and Ordinal Regression using the data on Treated group- Enterprises that joined business groups and Control groupEnterprises that did not join business groups were used and regressed for both the treated and control combined and for the treated only and control only.

The Hypothesis that was tested- Use of business groups has a positive effect on financial performance of the informal micro retail enterprises and used the difference of two populations/samples using mean or $\mathrm{P}$ value
- $\mathrm{H}_{0^{-}}$Null Hypothesis- Financial performance of enterprises in business groups $\leq$ financial performance of enterprises not in business groups

- $\mathrm{H}_{1}$ - Alternative Hypothesis- Financial performance of enterprises in business groups > financial performance of enterprises not in business groups

To increase the efficiency of the estimates, the study followed Sayingzoga, Bulte \& Lensink (2016) who include control variables (covariates).

The estimate followed the model equation by Drexler et al. (2014) below which was used to analyze the impact of training on micro enterprises in a study in Dominican Republic:

$$
\begin{aligned}
& \mathrm{PER}^{\mathrm{ALL}}=\alpha+\gamma_{2} \mathrm{FIN}^{\mathrm{ALL}}+\gamma_{3} \mathrm{MAN}^{\mathrm{ALL}}+\gamma_{4} \mathrm{STR}^{\mathrm{ALL}}+\gamma_{1} \mathrm{GRP}+\delta X i^{\mathrm{ALL}} \\
& +\varepsilon_{i}(2) \\
& \mathrm{PER}^{\mathrm{TRT}}=\alpha+\gamma_{5} \mathrm{FIN}^{\mathrm{TRT}}+\gamma_{6} \mathrm{MAN}^{\mathrm{TRT}}+\gamma_{7} \mathrm{STR}^{\mathrm{TRT}}+\delta X i^{\mathrm{TRT}}+\varepsilon_{i}(2 \mathrm{a}) \\
& \mathrm{PER}^{\mathrm{CON}}=\alpha+\gamma_{8} \mathrm{FIN}^{\mathrm{CON}}+\gamma_{9} \mathrm{MAN}^{\mathrm{CON}}+\gamma_{10} \mathrm{STR}^{\mathrm{CON}}+\delta X i^{\mathrm{CON}}+\varepsilon_{i}
\end{aligned}
$$$$
\text { (2b) }
$$

Where;

PER $^{\mathrm{ALL}}$-Financial Performance for all (treated and control) sample enterprises

PER $^{\text {TRT }}$ - Financial Performance for treated group only sample enterprises

PER $^{\mathrm{CON}}$ - Financial Performance for control group only sample enterprises

GRP - Group Participation Dummy (where 1 was a representation of Yes in group and 0 No not in group)

FIN ${ }^{\text {ALL }}$ - Financial Factors: "for all-treated and control group" (were obtained by the average aggregate from the loans, financial training and financial bookkeeping data)

FIN ${ }^{\text {TRT }}$ - Financial Factors: "for treated group only" (were obtained by the average aggregate from the loans, financial training and financial bookkeeping data)

FIN ${ }^{\mathrm{CON}}$ - Financial Factors: "for control group only" (were obtained by the average aggregate from the loans, financial training and financial bookkeeping data)

MAN ${ }^{\mathrm{ALL}}$ - Managerial Factors: "for all-treated and control group" (were obtained by the average aggregate from the inventory management, coaching and merchandizing data)

MAN"TRT - Managerial Factors: "for treated group only" (were obtained by the average aggregate from the inventory management, coaching and merchandizing data)

MANCON - Managerial Factors: "for control group only" (were obtained by the average aggregate from the inventory management, coaching and merchandizing data)

STR $^{\mathrm{ALL}}$ - Strategic Fit Factors: "for all-treated and control group" (were obtained by the average aggregate from the joint supplies sourcing, innovation partnerships and technology use data)

STR $^{\mathrm{TRT}}$ - Strategic Fit Factors: "for treated group only" (were obtained by the average aggregate from the joint supplies sourcing, innovation partnerships and technology use data) STR ${ }^{\mathrm{CON}}$ - Strategic Fit Factors "for control group only" (were obtained by the average aggregate from the joint supplies sourcing, innovation partnerships and technology use data)

$X i^{\mathrm{ALL}}$ - Vector of covariates: "for all-treated and control group (included age, level of education, gender, marital status, number of employees) 
$X i^{\text {TRT }}$ - Vector of covariates: "for treated group only" (included age, level of education, gender, marital status, number of employees)

$X i^{\text {CON }}$ - Vector of covariates: "for control group only" (included age, level of education, gender, marital status, number of employees)

Anderson (n.d.) recommends collecting of all controls/covariates that are most likely to confound on the relationship between the independent and dependent variable as a means of taking care of endogeneity problem. In the study various control variables were used. They conclude that in experimental designs, especially the ones with mediation, endogeneity exists from measurement errors, confounding variables and effects on selection.

\subsection{Reliability and Validity}

Reliability refers to consistency and replication and is concerned with the robustness of the questionnaire and whether or not it produces consistent findings under different conditions and different timings (Saunders et al., 2009). To assess reliability, the internal consistency approach was used which involves correlating responses to questions in the questionnaire to each other across a subgroup of questions. The Cronbach's alpha was used to measure internal consistency and the primary data obtained during the study was used to compute reliability. There were initial plans to have a pilot study, however, the number of the enterprises in the smart duka project were fixed as the study reference period was based on prior years and hence it proved difficult to get a different set of enterprises to do the pilot test on as the same enterprises would have been included in the final study which would have affected the participants responses hence affecting the study results. Internal validity refers to the ability of the questionnaire to measure what it is intended to measure also known as measurement validity. Internal validity occurs when the research shows a causal relationship between two variables, from the research results the results did show good measurement as the results were able to show the causal relationships between the dependent and independent variables using the correlation and regression analysis results hence confirming internal validity. Content validity which is the extent to which the questions provide adequate coverage to the investigative questions was checked based on the literature reviewed. Based on the literature reviewed there was adequate coverage of the sub factors under each of the factors and performance section by having 2 questions covering each sub factor hence good content validity. External validity which refers to study's research findings being generalized to other relevant groups was checked to see if statistical generalisability can be used using the results of both the treated and control group which were in sync across the business factor data and the financial performance data hence indicating external validity.

This study is based on an experiment/project using quantitative data. The quality of the research was assessed on the randomness that the control and treated group were created, and the presence of a control group removing any possible effects of an alternative explanation to the intervention and eliminate threats to internal validity. The control group was subjected to the same external influences as the treated group apart from the group participation being tested.

\subsection{Reliability}

Reliability of the study instrument was determined to establish the level of consistency of study measurement over time. Using Cronbach's alpha coefficient values between 0 and 1.00 , Kothari (2012) stated that the rule of thumb for Cronbach's alpha is that the closer the alpha is to 1 the higher the reliability. Findings were presented in Table 3.2.

Table 3.2: Reliability Results

\begin{tabular}{lll}
\hline $\begin{array}{l}\text { Construct } \\
\text { Measurements }\end{array}$ & Cronbach's alpha & $\begin{array}{l}\text { Number } \\
\text { Items }\end{array}$ \\
\hline Financial factors & .712 & 6 \\
Managerial factors & .815 & 6 \\
Strategic-fit factors & .865 & 6 \\
Financial & .923 & 6 \\
performance & & \\
\hline
\end{tabular}

Source: Research Findings (2020)

Findings in Table 3.2 established that the Cronbach's alpha for all the study variables was above .7 or closer to 1.00 , hence the research instrument was considered reliable and was used in the study. The reliability of the constructs was deemed excellent in establishing internal consistency, suggesting that the instrument of the study was applicable in giving consistent results over time.

\section{FINDINGS}

\subsection{Financial Factors}

This section is aimed to assess the significance of the differences of various financial factors between the treated and control groups of micro enterprise under Smart Duka programme. Tests statistics from Mann Whitney U test were used to interpret the study findings as presented in table 4.8. Likert scale of 1-5 had been used with 5 being most favourable. 
Table 4.8: Financial Factors Descriptive Results

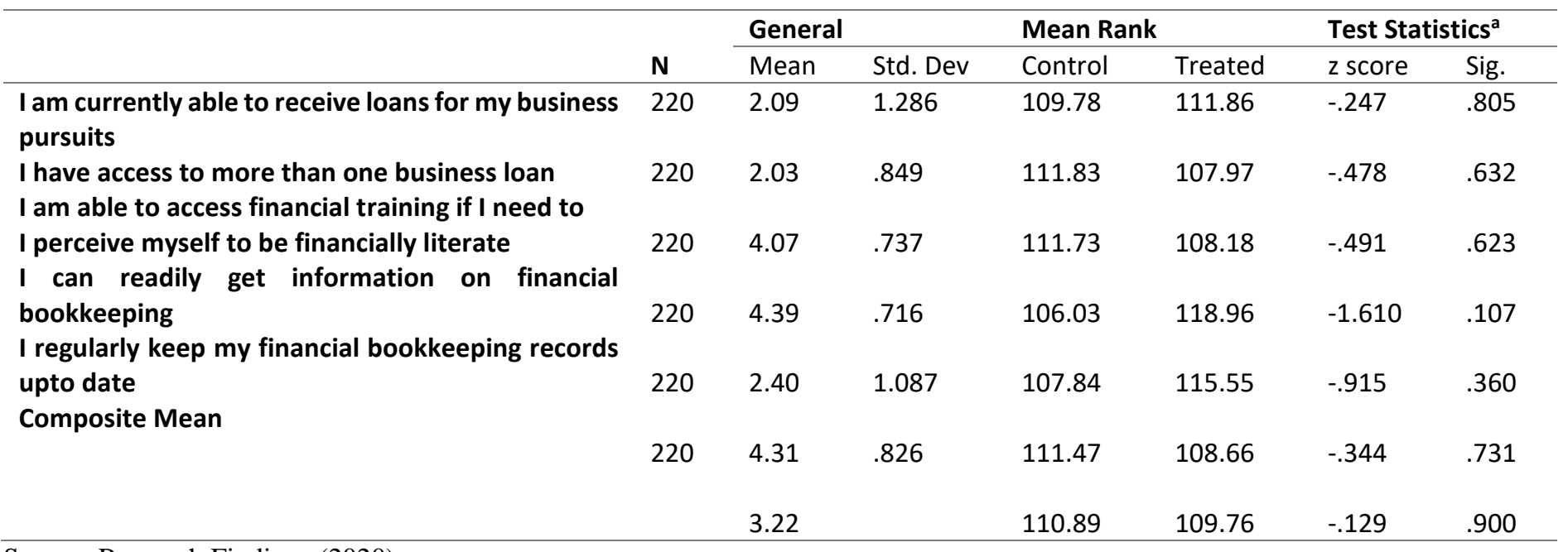

Source: Research Findings (2020)

(Table 4.8) presents the findings on financial factors of the study. The overall composite mean of 3.22 clearly illustrate that respondents agreed that financial factors are critical for the success of the business. This was supported by the fact that across the two groups of the study, majority with a mean of 4.39 agreed that they perceive themselves to be financially literate. Also, respondents with a mean of 4.31 and 4.07 agree that they can regularly keep their financial bookkeeping records upto date and that they are able to access financial training if they need to respectively. The study also presented the mean findings of the two groups of the study using mean rank. The overall composite mean rank of control group was 110.89 while that of treated group was 109.76 . The Control group had a higher ranking in terms of financial factors. There was slight difference between the groups. Using test statistics, findings revealed that across the two groups of the study, there was insignificant difference of application of financial factors in their businesses. Overall significance value of $.900>.05$ confirms that challenges of financial accessibility remains common for the two groups of businesses (table 4.8). Thus, despite the difference of mean rank being higher for the control group the difference between the two groups was statistically insignificant. The findings of this study therefore disagrees with the study findings of Kodongo and Kendi (2013) whose study insinuated that enterprises in groups may apply financial factors effectively than individual enterprises.

Further, respondents in these two groups of the study also disagreed that they are currently able to receive loans for their business pursuit (mean $2.09<3.0$ ); as well as being unable to have access to more than one business loan (mean $2.03<3.0$ ). Based on these findings, the study can affirm that despite efforts made by the programme to enhance financial aspects of these micro enterprises, financial factors especially access to various loans remains a challenge for many business. Therefore, programmes to educate these micro enterprises how they can have access to capital or ease loan availability and improve their bookkeeping would be important as suggested by Tinajero and Lopez-Acevedo (2010).

\subsection{Managerial Factors}

This section is aimed to assess the significance of the differences of various managerial factors between treated and control groups of micro enterprise under Smart Duka programme. Tests statistics from Mann Whitney $U$ test were used to interpret the study findings as presented in table 4.9.

The second objective of the study was to assess the effect of managerial factors on financial performance of micro enterprises. The findings (table 4.9) revealed that there was a composite mean of $3.35>3.0$ for the study. This could imply that respondents across the two groups of the study agree that managerial factors are effective in enhancing performance of the business. This finding is in agreement with the previous finding of Asah, Olufunzo et al (2015) who found out that strategic planning, and efficient management of enterprises resources can efficiently enhance enterprise performance and growth. This was supported by the findings that respondents strongly agreed that I have been able to organize my shop in a manner appealing to my customers through merchandising, with an overall mean of 4.15 for the two groups. They also agreed that they have been able to get more customers due to the merchandising managerial concept introduced to them during the course of project period with an overall mean of 4.73 (table 4.9). Merchandizing is a practise of arranging and displaying goods in an orderly manner which is appealing to the customers and helps customers identify what they need easily and identify product information easily like pricing. Likert scale of 1-5 had been used with 5 being most favourable. 
Table 4.9: Managerial Factors Descriptive Results

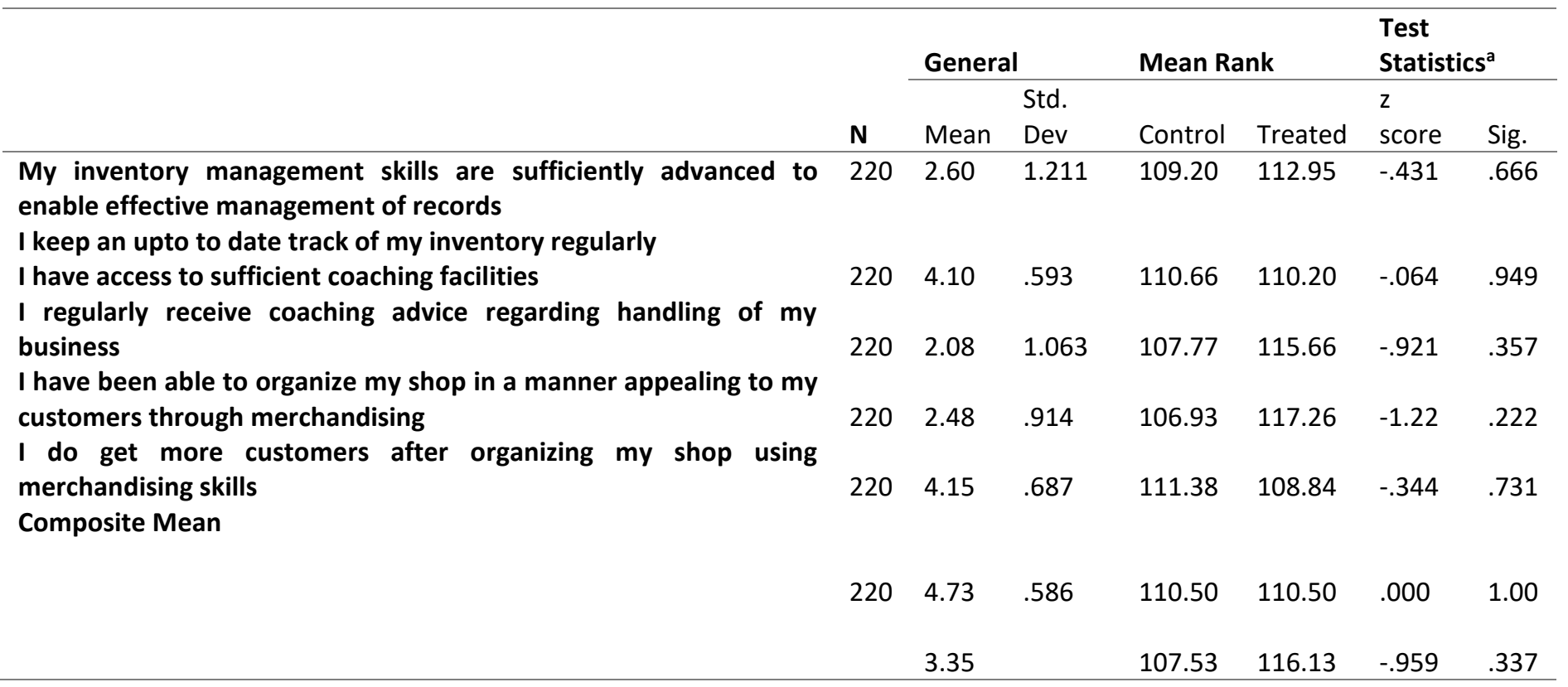

Source: Research Findings (2020)

While aspects of merchandising was considered effective for the success of performance of micro enterprises by the respondents, the respondents also indicated that they disagree that they have had sufficient coaching facilities, with a mean of $2.08<$ 3.0 (table 4.9). However, this low ranking aspect is due to the fact that coaching is done intensively during the project period when funding of the programme is ongoing hence the coaching intensity was not felt as much after this. The issues disagreed upon by the respondents who are business owners, have indeed been mentioned by Solly (2016) whose study argued that managerial issues such as coaching remain critical factors that may hinder the performance of SMEs. That is, lack of professionalism and efficient coaching practices for micro enterprise owners may hinder efficient management of business resources. From the mean rank findings, the study established control group had a mean rank of 107.53 while treated group had a mean rank of 116.13. The Treated group had a higher ranking in terms of managerial factors. Using test statistics to establish the difference between the group of the study based on managerial factors, findings indicated a significance value of $.337>.05$, suggesting that there is no significant difference in managerial factors across the two groups of the study. Thus, despite the difference of mean rank being higher for the treated group the difference between the two groups was statistically insignificant.

\subsection{Strategic Fit Factors}

This section describes the assessment of significance of the differences of various strategic fit factors between the treated and control groups of micro enterprise involved in the programme of the study. Mann Whitney U test statistics were used as shown in table 4.10.

Table 4.10: Strategic Fit Factors Descriptive Results

\begin{tabular}{|c|c|c|c|c|c|c|c|}
\hline & \multirow[b]{2}{*}{ Obs } & \multicolumn{2}{|c|}{ General } & \multicolumn{2}{|c|}{ Mean Rank } & \multicolumn{2}{|c|}{ Test Statistics $^{\mathrm{a}}$} \\
\hline & & Mean & Std. Dev & Control & Treated & z score & Sig. \\
\hline $\begin{array}{l}\text { I have partnered with other businesses to get } \\
\text { better deals on orders }\end{array}$ & 220 & 2.11 & 1.023 & 106.84 & 117.43 & -1.227 & .220 \\
\hline I get tips on better prices from other businesses & 220 & 2.85 & 1.210 & 106.26 & 118.54 & -1.428 & .153 \\
\hline $\begin{array}{l}\text { I have engaged with other businesses to come up } \\
\text { with innovative solutions to problems } \\
\text { I have learnt other ways of handling business } \\
\text { issues or business ventures from other businesses }\end{array}$ & 220 & 2.69 & .986 & 107.25 & 116.66 & -1.091 & .275 \\
\hline $\begin{array}{l}\text { I have used technology to improve the efficiency of } \\
\text { my business }\end{array}$ & 220 & 2.25 & 1.264 & 108.55 & 114.20 & -.656 & .512 \\
\hline $\begin{array}{l}\text { I have access to a smartphone that I can use in my } \\
\text { business } \\
\text { Composite Mean }\end{array}$ & 220 & 2.26 & .897 & 107.22 & 106.72 & -1.111 & .267 \\
\hline
\end{tabular}




$\begin{array}{rrrrrrr}220 & 4.22 & .641 & 108.07 & 115.11 & -.918 & .359 \\ & & & & & & \\ & 2.73 & & 105.49 & 120.00 & -1.615 & .106\end{array}$

Source: Research Findings (2020)

The third objective of the study sought to determine the effect of strategic fit factors (joint supply sourcing, innovation partnership and technological use) on the financial performance of micro enterprise businesses in the programme of the study. Findings as presented in (table 4.10), clearly indicate that respondents across the groups of the study did not entirely agree (disagree) that strategic fit factors has been effective in the performance of the informal micro enterprises (composite of 2.73 < 3.0). This is because respondents across the study groups disagreed that they have partnered with other businesses to get better deals (mean of $2.11<3.0$ ). Despite majority of the respondents agreeing that they have access to smartphones that they can use in their business (mean of $4.22>3.0$ ), they also disagreed that they have used technology to improve the efficiency of their business (mean of $2.26<3.0$ ). Findings also showed that respondents disagreed that they get tips on better prices from other businesses (mean of $2.85<3.0$ ). The study findings therefore did not fully support Kibry and Kaiser (2003) whose study found out that joint-ventures and group participation improves the competencies, and allow for the common sourcing of resources for businesses by the enterprises.

Using the mean rank findings, the study showed that the overall mean rank for control group of the study was 105.49 while mean rank for treated group was 120.00 . The Treated group had a higher ranking in terms of strategic fit factors. Test statistics based on the significance value of the study indicated that all the constructs of strategic fit factors across the groups of the study were as insignificant. That is, they all had a significance value above .05 . Overall significance value of $.106>0.05$ suggested that there was no significance difference in effective of usage and benefits of strategic fit factors across the two groups of the study. Overall, the observation was that the level of strategic fit factor is ineffective. Also to note is that, despite treated group having some strategic fit such as better deals, the level of effectiveness of the factor in these businesses has been low. This is despite studies such as Hoffman and Schlosser (2001) indicating that strategic alliances are currently gaining popularity across businesses with the aim of enhancing enterprise competencies. Thus, despite the difference of mean rank being higher for the treated group the difference between the two groups was statistically insignificant.

\subsection{Financial Performance}

The study examined the financial performance of informal micro enterprises of Smart Duka Programme by examining level of agreements on the previous performance of the business. Using performance constructs, the study used Mann Whitney U test statistics to indicate the significance difference in performance between the two groups of the study.

The study aimed to establish performance of the informal micro enterprises across the study groups, as well as the difference in performance between the groups, using Mann Whitney U test for significant difference. First, the study established as presented (table 4.11) the overall performance of the two groups. Composite mean of $3.56>3.0$ showed that respondents agreed that performance of the businesses across the groups have been fair or good. This was in accordance with respondents agreement that over the past two years, they have been able to increase their inventory (mean of $3.63>3.0$ ), over the two years, I have seen my shop increase in size (mean of $3.80>3.0$ ) (table 4.10). Across all the constructs of performance, respondents agreed that the business have been faring well (general mean above 3.0).

The study also established mean ranks for each groups of the study. Overall mean rank established that control group had a mean rank of 104.95 while treated group had a mean rank of 121.01. The Treated group had a higher ranking in terms of financial performance factors. Using test statistics of significance value, findings established that there was a significant difference between the two groups based on the performance of the businesses in the last two years. That is, treated group have performed better than control as indicted by a significance value < .05 in 3 of the factors under financial performance on increase in inventory, increase in profit and more access to cash float over the last 2 years. However, the overall significance value of $.074>.05$ established insignificant difference in performance of informal micro enterprises in control and treated groups (table 4.11). Thus, despite the difference of mean rank being higher for the treated group the difference between the two groups was statistically insignificant.

Table 4.11: Financial Performance Descriptive Results

\begin{tabular}{llllllll}
\hline & & \multicolumn{2}{c}{ General } & \multicolumn{2}{c}{ Mean Rank } & \multicolumn{2}{c}{ Test Statistics $^{\mathrm{a}}$} \\
\cline { 3 - 8 } & $\mathbf{N}$ & Mean & Std. Dev & Control & Treated & z score & Sig. \\
\hline $\begin{array}{l}\text { Over the past two years I have been able to } \\
\text { increase my inventory }\end{array}$ & 220 & 3.63 & 1.067 & 104.95 & 121.01 & -2.111 & .035 \\
$\begin{array}{l}\text { Over the past two years I have seen my shop } \\
\text { increase in size }\end{array}$ & 220 & 3.80 & 1.027 & 105.33 & 120.29 & -1.775 & .076 \\
$\begin{array}{l}\text { Over the past two years I have seen a significant } \\
\text { increase in sales }\end{array}$ & 220 & 3.65 & .969 & 106.34 & 118.38 & -1.462 & .144 \\
& 220 & & & & & & \\
\end{tabular}

This publication is licensed under Creative Commons Attribution CC BY.

http://dx.doi.org/10.29322/IJSRP.11.06.2021.p11435

Www.ijsrp.org 


$\begin{aligned} & \text { Over the past two years I need to replenish my } \\ & \text { stock more often as most of my stock is quickly } \\ & \text { depleted due to faster sales }\end{aligned}$
$\begin{aligned} & \text { Over the past two years I have noted a significant } \\ & \text { increase in profit }\end{aligned}$

Source: Research Findings (2020)

\section{Inferential Statistics}

This section aimed at providing critical information for making study conclusions. Four main sets of analysis were applied. First, the study estimated the correlation analysis, robustness or test of model significance, Kruskal wallis which is a non-parametric one way ANOVA analysis and regression coefficient which forms part of regression analysis. Ordinal regression analysis was performed since the study used ordinal data.

\section{Correlation analysis}

To assess the correlation analysis, the study used Spearman's correlation coefficient which measures the strength of relationship between variables in the study (financial factors, managerial factors, strategic fit factors and financial performance). The Spearman's coefficient ranges between -1 and +1 . A negative coefficient value shows negative correlation whereas a positive coefficient shows positive correlation. However, a coefficient value of 0.5 and above was considered strong while below 0.3 was considered weak.

The Spearman's correlation coefficient summary shown on table 4.12 reveals that the correlation between managerial factors and strategic fit factors with financial performance was positive and significant; at significant level of 0.05 and 0.01 . This was established after determining the differences between treated and control micro enterprise groups of the study. The correlation analysis to find out the strength of relationship between financial factors measured by (loans, group financial trainings and financial bookkeeping) and financial performance was insignificantly correlated $(\mathrm{r}=.024, \mathrm{p}>0.05)$. This indicated a weak positive and insignificant correlation between financial factors and financial performance of group informal micro enterprises. The study also established a positive significant correlation between managerial factors measured by (inventory management, coaching and merchandising $)$ and financial performance $(r=.169, \mathrm{p}<0.05)$.

\section{Table 4.12: Spearman's Correlation Coefficient Results}

\begin{tabular}{|c|c|c|c|c|c|c|}
\hline \multicolumn{7}{|l|}{ Correlations } \\
\hline & & $\begin{array}{l}\text { Financial } \\
\text { performance }\end{array}$ & $\begin{array}{l}\text { Financial } \\
\text { factor }\end{array}$ & $\begin{array}{l}\text { Managerial } \\
\text { factor }\end{array}$ & $\begin{array}{l}\text { Strategic fit } \\
\text { factor }\end{array}$ & Group \\
\hline \multirow{4}{*}{ performance } & $\begin{array}{l}\text { Spearman's Correlation } \\
\text { Sig. (1-tailed) }\end{array}$ & 1 & & & & \\
\hline & $\mathrm{N}$ & & & & & \\
\hline & & 220 & & & & \\
\hline & Spearman's Correlation & & & & & \\
\hline \multirow[t]{4}{*}{ Financial factor } & Sig. (1-tailed) & & & & & \\
\hline & $N$ & .024 & 1 & & & \\
\hline & & .364 & & & & \\
\hline & Spearman's Correlation & 220 & 220 & & & \\
\hline \multirow[t]{4}{*}{ Managerial factor } & Sig. (1-tailed) & & & & & \\
\hline & $\mathrm{N}$ & & & & & \\
\hline & & $.169 * *$ & $.381^{* *}$ & 1 & & \\
\hline & Spearman's Correlation & .006 & .000 & & & \\
\hline \multirow[t]{5}{*}{ Strategic fit factor } & Sig. (1-tailed) & 220 & 220 & 220 & & \\
\hline & $\mathrm{N}$ & & & & & \\
\hline & & $.194 * *$ & $.224 * *$ & $.368^{* *}$ & 1 & \\
\hline & & .002 & .000 & .000 & & \\
\hline & & 220 & 220 & 220 & 220 & \\
\hline \multirow[t]{2}{*}{ Group } & $\begin{array}{l}\text { Spearman's Correlation } \\
\text { Sig. (1-tailed) }\end{array}$ & $.121^{*}$ & -0.009 & .065 & .109 & 1 \\
\hline & $\mathrm{N}$ & .037 & .450 & .169 & .053 & \\
\hline
\end{tabular}


220

220

220

220

220

**Correlation is significant at the 0.01 level (1-tailed)

*Correlation is significant at the 0.05 level (1-tailed)

Source: Author (2020)

This revealed a weak but significant relationship between the variables. Lastly, the findings established a weak but significant positive correlation between strategic fit factors measured by (joint suppliers sourcing, innovation partnership and technology) and financial performance $(r=.194, p<0.05)$. Of the three variables of the study, the study established that both strategic fit and managerial factors had a significant but weak positive correlation with financial performance. However, financial factors had insignificant weak positive correlation as presented in table 4.12.

Further, a correlation analysis on business group (treated and control) and financial performance of informal micro enterprises established a weak but significant positive correlation $(r=0.121$, $\mathrm{p}<0.05)$ as shown in table 4.12. This finding reaffirmed the findings of Siekei, Wagoki and Kalio (2013) whose study found out that businesses that tend to participate in groups are more effective than individual businesses. They gave out reasons such as training, coaching and partnership as reasons why these businesses get through group participation, unlike individual micro enterprises. The findings were also echoed by Kibry and Kaiser (2003) who indicated that joint ventures have high level of competencies compared to individually managed ventures.

\subsubsection{Regression Analysis}

Ordinal Regression analysis was carried out to establish the relationship between independent variables (financial factors, managerial factors and strategic fit factors) and dependent variable (financial performance) of the study. The analysis was assessed to show the effect of financial factors, managerial factors and strategic fit factors on financial performance of micro enterprises. The analysis was based on the equation (2) of the study as discussed on methodology section of the study.

\subsubsection{Model Summary}

Model summary was estimated to establish percentage of variation in the financial performance of informal micro enterprises caused by factors in business groups such as financial factors, managerial factors and strategic fit factors using Pseudo R-Squares. As shown in table 4.13, Pseudo R-Square has three squared values. For explaining the percentage change on financial performance of informal micro enterprises caused by independent variables, the study uses Nagelkerke R-Square value of .150. This explains that that $15.0 \%$ of changes in financial performance of informal micro enterprises involved in the study are caused by changes in financial factors, managerial factors and strategic fit factors, together with control factors. This implies that other changes $(85.0 \%)$ may be caused by other factors not included in the study. Correlation coefficient which reveals the relationship of study variables is explained by Cox and Snell R-Square value of .015 , which indicates that there is a positive relationship between study variables.
Table 4.13: Model Summary

Pseudo R-Square

$\begin{array}{ll}\text { Cox and Snell } & .150 \\ \text { Nagelkerke } & .150 \\ \text { McFadden } & .030\end{array}$

Link function: Logit. Source: Author (2020)

4.6.2.2

Model Fitting

Table 4.14: Model Fitting-Ordinal Regression

Model Fitting Information

\begin{tabular}{lllll}
\hline & $\begin{array}{l}\mathbf{- 2} \text { Log } \\
\text { Likelihood }\end{array}$ & $\begin{array}{l}\text { Chi- } \\
\text { Square }\end{array}$ & df & Sig. \\
\hline $\begin{array}{lllll}\text { Intercept Only } \\
\text { Final }\end{array}$ & $\begin{array}{l}1204.668 \\
1168.969\end{array}$ & 35.700 & 13 & .001 \\
\hline \multicolumn{5}{c}{ Link function: Logit. } \\
\multicolumn{2}{c}{ Source: Research Findings (2020) }
\end{tabular}

Table 4.15: Model Fitting-Generalized linear model-ordinal logistic

Omnibus Test ${ }^{\mathrm{a}}$

\begin{tabular}{lll}
\hline & $\begin{array}{l}\text { Likelihood } \\
\text { Ratio Chi- } \\
\text { Square }\end{array}$ df Sig. \\
\hline & 35.700 & $13 \quad .001$ \\
\hline a. Compares the fitted model against the
\end{tabular}

thresholds-only model

Source: Research Findings (2020)

Logistic regression is based on logit which deals with the natural logarithm of an odds ratio and are used to test hypotheses on relationships of an outcome variable that is categorical and one or more predictor variables that are categorical or continuous (Peng et al., 2002). The logit is the natural log of the odds or expressed as probability/(1-probability). The Chi-Square in (table 4.14) using ordinal regression is the Likelihood Ratio (LR) ChiSquare test. It tests whether at least one of the independent's regression coefficient is not equal to zero in the model of the study and can be established by $(1204.668$ - $1168.969=35.700)$. Significance (Sig.) is the probability of getting a LR statistic above the null hypothesis which assumes that regression coefficients of independent variables are zero and that the intercept only/null model is better than the final model.

The Chi-Square test, tests if there is significant improvement in fit of final model relative to intercept only model. The study established a significance level $(\mathrm{p}=.001<.05)$ which shows that at least one of the regression coefficients in the model is not equal to zero, and that the model is fit and shows significant improvement in fit of final model relative to intercept only model at significance level of $.001<.05$. The Likelihood ratio ChiSquare from omnibus test as shown in table 4.15 using generalized linear model- ordinal logistic gave the same results as the ordinal 
regression under Ordinal regression results on table 4.14 hence providing legitimacy to the ordinal regression results which were similar to the generalized linear model-ordinal logistic.

\section{Goodness of Fit}

The study performed goodness of fit to estimate whether data for the study is consistent with the model or if data fits the model as shown in table 4.16 .

Table 4.16: Goodness of Fit

Goodness of-Fit

\begin{tabular}{llll}
\hline & $\begin{array}{l}\text { Chi- } \\
\text { Square }\end{array}$ & df & Sig. \\
\hline Pearson & 3862.238 & 4523 & 1.000 \\
Deviance & 1168.969 & 4523 & 1.000 \\
\hline
\end{tabular}

Link function: Logit

Source: Author (2020)

Table 4.16 presents Goodness of fit results. The null hypothesis states that the model in use is adequate in comparison to a perfect model with all cell counts and is a good model fit to data (Peng et al., 2002). The study established a significance value $(\mathrm{p}=1.000>.05)$ which reveals that data fits the model of the study and the model is adequate in comparison to a perfect model.

Kruskal Wallis Test

The Kruskal Wallis test which is the non- parametric one way ANOVA was done with results presented in table 4.17 from the results all the factors and covariates were non significantly different from the two groups-Treated and control as the significance levels were all $>0.05$. The significance results were similar to the significance under descriptive results in table 4.8, $4.9,4.10$ and 4.11 and demographic summary statistics in table 4.2.

Table 4.17:Kruskal Wallis Test Kruskal Wallis-Test Statistic ${ }^{a, b}$

\begin{tabular}{lllll}
\hline & $\begin{array}{l}\text { Financial } \\
\text { Factors }\end{array}$ & $\begin{array}{l}\text { Managerial } \\
\text { Factors }\end{array}$ & $\begin{array}{l}\text { Strategic } \\
\text { Fit } \\
\text { Factors }\end{array}$ & $\begin{array}{l}\text { Financial } \\
\text { Performance } \\
\text { Factors }\end{array}$ \\
\hline Kruskal & .016 & .920 & 2.609 & 3.197 \\
Wallis & 1 & 1 & 1 & 1 \\
H & .900 & .337 & .106 & .074 \\
df & & & & \\
Asymp. & & & & \\
Sig. & & & & \\
\hline
\end{tabular}

\begin{tabular}{lllll}
\hline Age & Gende & Marita & Educatio & No. of \\
& $\mathbf{r}$ & I & $\mathbf{n}$ & employee \\
& & Status & & s \\
\hline
\end{tabular}

\begin{tabular}{|c|c|c|c|c|c|}
\hline Kruska & 3.66 & 1.602 & .464 & 723 & 638 \\
\hline I Wallis & 6 & 1 & 1 & 1 & 1 \\
\hline H & 1 & .206 & .496 & .395 & .425 \\
\hline df & .056 & & & & \\
\hline \multicolumn{6}{|l|}{ Asymp } \\
\hline . Sig. & & & & & \\
\hline
\end{tabular}

Source: Research Findings (2020)

4.6.2.5 Regression Coefficients/Estimates

To accept or reject the null hypothesis of the study, regression estimates with a significance level of 0.05 was used to estimate the effect and extent of effect of financial factors, managerial factors and strategic fit factors on financial performance. Control factors/variables were also included in the model. Ordinal regression was estimated and findings presented in table 4.18 .

Table 4.18 presents the findings on ordinal regression estimates which were similar to the generalized linear modelordinal logistic. The study established that of the three predictor variables of the study; that is, financial factors, managerial factors and strategic fit factors; only financial factors had a negative estimate on financial performance $(\beta=-.164)$. Both managerial and strategic factors had positive estimates of $(\beta=.381)$ and $(\beta=$ $.596)$ respectively. Both financial factors $(\mathrm{p}=.597>.05)$ and managerial factors $(.198>.05)$ had insignificant effect on the performance. However, managerial factors had insignificant positive relationship while financial factors had insignificant inverse relationship with performance of informal micro enterprises in the study. Only strategic fit factor as a predictor variable of the study had significant strong positive relationship ( $p$ $=.004<.05)$ with financial performance of informal micro enterprises in the study. For the managerial and strategic fit factors which had positive estimates, this means with increasing scores of the managerial and strategic fit factors there are increased chances of falling at a higher level of the financial performance variable. However, for the financial factors which had a negative estimate, this means as the financial factors increase there is decreased probability of falling at a higher level on the financial performance variable.

Therefore, from the data extracted from table 4.18, the regression equation was based on the equation (2) of the study. This indicates that if all factors were held constant; financial performance of the control and treated informal micro enterprise groups would be at 12.348 on the higher level as presented on table 4.18 . 
Parameter Estimates

Table 4.18: Regression Estimates Results

\begin{tabular}{|c|c|c|c|c|c|c|c|c|}
\hline & & \multirow[b]{3}{*}{ Estimates } & \multirow[b]{3}{*}{$\begin{array}{l}\text { Std. } \\
\text { Error }\end{array}$} & \multirow[b]{3}{*}{ Wald } & \multirow[b]{3}{*}{ df } & \multirow[b]{3}{*}{ Sig. } & \multirow{2}{*}{\multicolumn{2}{|c|}{ 95\% Confidence }} \\
\hline & & & & & & & & \\
\hline & & & & & & & $\begin{array}{l}\text { Lower } \\
\text { Bound }\end{array}$ & $\begin{array}{l}\text { Upper } \\
\text { Bound }\end{array}$ \\
\hline \multirow[t]{2}{*}{ Threshold } & {$[\mathrm{ses}=1.333]$} & 1.057 & 2.322 & .207 & 1 & .649 & -3.494 & 5.607 \\
\hline & [ses $=4.666]$ & 12.348 & 2.403 & 26.408 & 1 & .000 & 7.638 & 17.057 \\
\hline \multirow[t]{4}{*}{ Location } & Financial factors & -.164 & .310 & .280 & 1 & .597 & -.772 & .444 \\
\hline & Managerial factors & .381 & .296 & 1.257 & 1 & .198 & .199 & .960 \\
\hline & Strategicfit factors & & & & & & & \\
\hline & & .596 & .209 & 8.155 & 1 & .004 & .187 & 1.005 \\
\hline \multirow[t]{3}{*}{ [2] } & Group & & & & & & & \\
\hline & Treated & .254 & .256 & .986 & 1 & .321 & -.755 & .247 \\
\hline & Control & $0^{\mathrm{a}}$ & . & . & 0 & . & . & . \\
\hline \multirow[t]{19}{*}{ [3] } & Age & & & & & & & \\
\hline & (<25 Years) & -.540 & .805 & .449 & 1 & .503 & -2.119 & 1.039 \\
\hline & (25-35 Years) & -.055 & .263 & .043 & 1 & .835 & -.570 & .461 \\
\hline & (>35 Years) & $0^{\mathrm{a}}$ & & . & 0 & . & . & \\
\hline & Gender & & & & & & & \\
\hline & Male-1 & .012 & .245 & .002 & 1 & .962 & -.468 & .491 \\
\hline & Female-2 & $0^{\mathrm{a}}$ & & 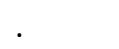 & 0 & . & . & \\
\hline & Marital-Status & & & & & & & \\
\hline & Married-1 & .990 & .595 & 2.763 & 1 & .096 & -.177 & 2.156 \\
\hline & Divorced-2 & -1.514 & 1.388 & 1.188 & 1 & .276 & -4.235 & 1.208 \\
\hline & Single-3 & $0^{\mathrm{a}}$ & ${ }^{\circ}$ & . & 0 & . & . & . \\
\hline & Education & & & & & & & \\
\hline & Tertiary-1 & .603 & .486 & 1.537 & 1 & .215 & -.350 & 1.556 \\
\hline & Secondary-2 & -.143 & .431 & .110 & 1 & .740 & -.988 & .702 \\
\hline & Primary-3 & $0^{\mathrm{a}}$ & . & . & 0 & . & . & . \\
\hline & No. of employees & & & & & & & \\
\hline & 1 person & 3.365 & 1.852 & 3.302 & 1 & .069 & -.265 & 6.995 \\
\hline & 2-5 people & 3.324 & 1.943 & 2.926 & 1 & .087 & -.485 & 7.133 \\
\hline & 6-9 people & $0^{\mathrm{a}}$ & & & 0 & . &. & - \\
\hline \multirow[t]{4}{*}{ (4)Location } & Financial factors & -.546 & .514 & 1.131 & 1 & .288 & -1.553 & .460 \\
\hline & Managerial factors & .485 & .467 & 1.078 & 1 & .299 & -0.431 & 1.400 \\
\hline & Strategicfit factors & & & & & & & \\
\hline & & .091 & .403 & .051 & 1 & .821 & .698 & 0.880 \\
\hline \multirow[t]{4}{*}{ (5)Location } & Financial factors & .199 & .407 & .238 & 1 & .626 & -.600 & .997 \\
\hline & Managerial factors & .282 & .404 & .489 & 1 & .484 & .509 & 1.073 \\
\hline & Strategicfit factors & & & & & & & \\
\hline & & .796 & .257 & 9.548 & 1 & .002 & .291 & 1.300 \\
\hline
\end{tabular}

Link function: Logit

a. This parameter is set to zero because it is redundant

(2) Group participation regression coefficient

(3) Control factors as presented in equation (2)

(4) Treated group regression coefficients with control factors as presented in equation (2a)

(5) Control group regression coefficients with control factors as presented in equation (2b)

Source: Research Findings (2020)

However, with changes such as unit increase in managerial factors and strategic fit factors, there is a predicted increase of .381 and .596 respectively of log odds of falling at a higher level of the financial performance of informal micro enterprises. As for a unit increase in financial factors, there is a predicted decrease of
.164 of $\log$ odds of falling at a higher level of the financial performance of informal micro enterprises. This therefore implies that only managerial and strategic fit factors variables have a positive effect on the financial performance of informal micro enterprises of the study, with managerial factor having 
insignificant positive effect and strategic fit factor having significant strong positive effect on financial performance. Also, strategic fit factor was the most dominant factor as it contributes $59.6 \%$ of changes in the financial performance of the informal micro enterprises.

It was followed by managerial factor which contributes $38.1 \%$ on the performance of informal micro enterprises as shown in table 4.18. These findings are in agreement with the previous findings of Asah, Olufunso et al (2015) whose study indicated that strategic planning through applying effective management practices such as coaching and merchandising which entails arrangement of products/resources of the micro enterprises can enhance enterprise growth. Also, Hoffman and Schlosser (2001) affirmed that businesses that form strategic alliances through groups attain business competencies which assist in micro enterprise management and pricing, leading growth of the business.

Parenthesis [2] in table 4.18 indicates the estimates of group effect. Findings shows that group factor have insignificant positive effect on performance of informal micro enterprises $(\beta=.254$, $\mathrm{p}$ $=.321>.05)$. Based on the findings in parenthesis [2], this means with increasing scores of the group participation (treated group) relative to the enterprises not in groups (control group) there are increased chances of falling at a higher level of the financial performance variable although these is statistically insignificant. With unit increase in group participation, there is a predicted increase of .254 of $\log$ odds of falling at a higher level of the financial performance of informal micro enterprises. The study also presented findings on control factors as shown in table 4.18 in parenthesis [3]. Of all the control variables of the study; age, gender, education, marital status and number of employees, none had significant effect on the performance of informal micro enterprises. All had significance values $>.05$. This is similar to the significance results on the demographic summary statistics on table 4.2.

The study also presented findings on treated group data based on equation ( $2 \mathrm{a}$ ) as shown in table 4.18 in parenthesis [4]. Of all the factors -financial, managerial and strategic fit factors were statistically insignificant, all had significance values $>.05$. The managerial and strategic fit factors had positive estimates while the financial factors had negative estimate which would increase and decrease respectively the probability of falling at a higher level of the financial performance. It was only the managerial factor estimate that was higher under treated group in comparison to control group

The study also presented findings on control group data based on equation (2b) as shown in table 4.18 in parenthesis [5]. Of all the factors -financial and managerial factors were statistically insignificant, had significance values $>.05$ while strategic fit factors were statistically significant, had significance values $<0.05$. All factors, financial, managerial and strategic fit factors had positive estimates which would increase the probability of falling at a higher level of the financial performance. The financial and strategic fit factors had higher estimates in the control group in comparison to the treated group while the strategic fit factor was significant in the control group while in the treated group it was not.

\section{DISCUSSION, CONCLUSIONS AND RECOMMENDATIONS}

\subsection{Discussion of the Findings}

This section discusses findings of the study based on the research objectives. The study was guided by three specific objectives; to assess the effect of financial factors, managerial factors and strategic fit factors in business groups on financial performance of informal micro retail enterprises in the Smart Duka Project. The analysis of the study was based on business groups. Micro enterprises in the group were referred to as treated group while those not in groups were referred to as control group. Difference in difference analysis using Mann Whitney $U$ test statistics was conducted at the descriptive level to determine how each factor performed across the business groups. Discussion of the study follows:

\section{Effect of business group financial factors on financial performance}

The first objective of the study was to assess the effect of financial factors in business groups on financial performance of informal micro retail enterprises in the Smart Duka project. Financial factors were measured by group based loans, group financial trainings and financial bookkeeping. From the descriptive findings, the results revealed that financial factors remain a major challenge for most businesses, both treated and control groups. Majority of the respondents indicated that accessibility to loan and frequent financial trainings on how to record sales have not been effectively mastered by the business owners. Despite having been coached on how to undertake bookkeeping practices so as to be able to track sales and financial performances, the findings revealed that most micro enterprises do not follow these practices. The mean ranking of the control group was above that of the treated group under the financial factors however, this difference was not statistically significant.

The study also established a correlation between financial factors and financial performance of the informal micro retail enterprises. The findings established a weak insignificant positive correlation between the variables of the study. One important assumption made during correlation analysis was based on the descriptive findings. This is because from the respondents' perspectives, micro enterprises still face financial factors challenges, both treated and control group. Only a few respondents confirmed that they could access loans and trainings. However, majority of the respondents indicated that most of their businesses are not doing well as a result of lack of access to enough funds to increase their inventories in the business. This finding agrees with previous studies (Tinajero \& Lopez-Acevedo, 2010), which have highlighted financial factors as a major challenge informal micro enterprises faces in the current business environment.

The study also determined the effect of financial factors on financial performance of micro enterprises using ordinal regression estimates analysis. The results shows that there exists insignificant negative relationship between financial factors in group business and financial performance. This was based on the p-value which is above the recommended significance level. Interestingly, the study also found out that inability to access capital, ineffective to turn financial skills in the business to achieve results can hinder business performance. In addition to 
having weak insignificant positive correlation, the study findings indicate that due to the aforementioned challenges that informal group micro enterprises face, most of these businesses cannot grow or expand. The findings concur with the findings of Kodongo and Kendi (2013) that even though group participation enhances business competencies and access to lending benefits, they remain challenges that must be addressed effectively in order to grow micro enterprises. Thus, there is insignificant negative effect of financial factors on financial performance. On the ordinal regression estimate results for the treated group of the businesses in groups the financial factors had a negative estimate that was insignificant while the control group of the businesses not in groups had a positive estimate that was insignificant. This does seem to tally to the findings on the descriptive results on mean rankings where the mean ranking of the control group was higher than the treated group although insignificant. Hence it seems for the financial factors, these seem to work better for the control group than the treated group and hence there is need to investigate more why this would be so. Although the current results show the difference is insignificant it does show that this could be a significant difference with time and with increased financial factors.

In summary, findings established that financial factors in business groups remain a major challenge that must be addressed effectively. With a weak positive correlation and insignificant inverse effect on the financial performance of informal micro enterprises in the programme, most respondents attributed these challenges to inability to access loans even within business groups as well as the inability to effectively utilize bookkeeping practices to grow their businesses. Across the business regions and/or areas of business, findings established that financial factors was a challenge across, both for treated and control business groups. Thus, there was insignificant spill over effects in relation to being in a group that can enhance chances of getting access to loans and other financial trainings. However, the composite mean in the descriptive results did clearly illustrate that respondents agreed that financial factors are critical for the success of the business but the level of administration seems to be causing the negative effect on financial performance from the loans, to financial bookkeeping and to financial training practices.

\section{Effect of business group managerial factors on financial performance}

The study also sought to assess the effect of managerial factors in business groups on financial performance of informal micro enterprises in the Smart Duka project. From the descriptive findings, the findings showed that respondents in both groups of the study unanimously agreed that managerial factors measured through inventory management, coaching and merchandising has been effective towards the performance of their businesses. Of importance to them was the merchandising concept which was introduced in the programme. Majority of the respondents agreed that they have been able to organize their shop in a manner appealing to the consumers/customers through merchandising. They also agreed that they do get more customers after organizing their shop using the skills they attained through merchandising practice training. The findings are in line with the study of Asah, Olufunso et al (2015) that organizing an enterprise in a way that appeals to the consumers is one of the strategic planning skills that businesses can learn through management practices to enhance their growth. There was no statistical significance difference in terms of managerial factors.

A correlation analysis was determined in the study between managerial factors in businesses and financial performance. The findings established that there a significant correlation between these two variables of the study. While the previous studies such as Solly (2016) indicated that managerial issues remain critical to the success of informal micro retail enterprises, the findings of the current study found that to these respondents especially those in business groups, the coaching they have received from various stakeholders in the business programme have significantly helped them to arrange their shops and manage their inventories in ways that appeal to the customers in the market. Also to note is of the three variables of the study, managerial factor had the second highest correlation coefficient value with financial performance of the business groups. Therefore, the study argue that across the business groups, that is, treated and control, respondents agreed that managerial factors has been effective towards their businesses. The mean ranking of the treated group was above that of the control group under the managerial factors however, this difference was not statistically significant.

The study further found out an insignificant positive relationship between managerial factors and financial performance of informal micro retail enterprises under Smart Duka project. The established higher $\mathrm{p}$-value (significance level) above the recommended level further revealed that managerial factor have insignificant positive effect on the performance of informal micro enterprises group businesses. Of the three variables of the study, findings reveal that managerial factors had the second highest positive regression estimate. This implies that increase in coaching, merchandising practices and inventory management increases the performance of the group businesses insignificantly compared to variable like financial factor. The finding agree with Atristain-Su (2018) that if business have professionalism, planning, decision making and communication skills, chances of growing are high. However, lack of all these can lead to closure or poor performing businesses. Thus, there is insignificant positive effect of managerial factors on financial performance. On the ordinal regression estimate results for the treated group of the businesses in groups, the managerial factors had a positive estimate that was insignificant but higher than the combined and control only group, however, in all instances they were insignificant. This does seem to tally to the findings on the descriptive results on mean rankings where the mean ranking of the treated group was higher than the control group although insignificant. Hence it seems for the managerial factors, these seem to work better for the treated group than the control group and hence there is need to investigate more why this would be so. Although the current results show the difference is insignificant it does show that this could be a significant difference with time and with increased managerial factors.

In establishing the Spillover effect of business trainings that treated group can pass to other micro enterprises, the results of the study established that for managerial factors which comprise of coaching, merchandising and other best management practices to some extent, there is insignificant positive spillovers effect. One 
assumption that the study made based on the findings of spillovers effect is that across the two groups of testing, merchandising was introduced to each of them. Meaning all the two groups undergo training, coaching and merchandising on similar occasion. This could be the reason as to why the spillovers effect is positively insignificant.

\section{Effect of business group strategic fit factors on financial performance}

The third and final objective of the study was to investigate the effect of strategic fit factors in business groups on financial performance of informal micro retail enterprises in the Smart Duka programme. Strategic fit factors were measured using joint suppliers sourcing, innovation partnerships and technology use. From the descriptive findings, both the tested groups; treated and control, agreed that to some extent they have been involved in joint supply sourcing business practice so as to easily access product at the lowest cost in the business. This supports the findings by Kibry and Kaiser (2003) who concluded that joint ventures, among other business competencies, allow for the common sourcing of raw materials and other resources for the micro enterprises. Respondents also agreed that indeed they have access to a smart phone that can be used in their businesses. However, the study also found out that most micro enterprises lack technological devices that they can use to track inventory management and sales in their businesses. This was supported by the insignificance values established between the two groups. The mean ranking of the treated group was above that of the control group under the strategic fit factors however, this difference was not statistically significant. From the descriptive findings, the findings showed that respondents in both groups using the composite mean ranked the strategic fit factors lowest in comparison to financial and managerial factors

Level of innovation partnerships however are still low across the businesses. The study established that most shop owners' objective in joint venturing or business groups is to get tips on better prices of the business, with little engagement with other businesses to come up with innovative solutions to their problems. A correlation analysis established that there is a statistical significant positive correlation between strategic fit factors and financial performance of micro enterprises business groups. Among the three variables of the study, strategic fit factor had the highest correlation coefficient value with performance of business groups under the programme of the study. This could be due to the ability of the business groups to bring informal micro enterprises owners together (Hoffman \& Schlosser, 2001), and allow them to identify business challenges and seek for better management practices that may impact their individual living standards as well as the growth of businesses within a given business region.

The study also estimated the ordinal regression estimate analysis between strategic fit factors and financial performance of business groups. Findings revealed that there was a significant strong positive relationship between these two variables of the study. This implies that strategic fit factor in the business group significantly affects their financial performances. Of the three variables of the study, strategic fit factors also had the highest positive effect on financial performance. However, analysing the treated group alone, the strategic fit factors were insignificant

This publication is licensed under Creative Commons Attribution CC BY

http://dx.doi.org/10.29322/IJSRP.11.06.2021.p11435 while for the control group and combined group these were significant. Hence there is need to investigate more on this cause of disparity. Thus, one of the assumption of the study findings is that when businesses form groups, they can easily access better pricing strategy and the business strategy that can allow them to grow their businesses during and after hard economic conditions. This is in accordance with the findings of Mungai and Ogot (2017) whose study concluded that micro enterprises need to use diverse competitive business strategy through value chain approaches, technology and networks so as to improve their performance. The spillover effect analysis in regards to strategic fit factors had a higher estimate in comparison showing the effect of spillover that is significant has a higher positive effect on financial performance.

\subsection{Conclusions}

The study made a number of conclusions and was discussed based on the research objectives of the study. The conclusion was drawn from the research discussion and findings of the study as discussed;

\section{Effect of business group financial factors on financial performance}

Based on the findings and discussion of the study, the study concluded that financial factors which entail group based loans, group financial training and financial bookkeeping remain a challenge for many micro enterprise businesses both in treated and control groups. Despite having an insignificant weak positive relationship with financial performance using the correlation results, the study also concluded that majority of the respondents agreed that they are still unable to receive loans, as majority do not have access to more than one loan. Most micro enterprises owners do not practice bookkeeping practices thus establishing monthly, quarterly, semi-annually and yearly sales is a challenge for them. None of the respondents in both treated groups were able to provide numerical sales volume of their businesses. From the regression analysis financial factors had insignificant negative effect on the financial performance of the businesses despite having a weak positive insignificant relationship from the correlation results. The control group had higher ranking mean compared to the treated group which were the enterprises in business groups under financial factors although insignificant. The spillover effect of financial factors was also found to be insignificant. The study therefore concluded that there is insignificant negative spillover effect of financial factors on financial performance of the informal micro businesses in the Smart Duka Project. Interventions are required to address the challenges since there is negative relationship between financial factors and performance of informal micro enterprises involved in the programme.

\section{Effect of business group managerial factors on financial performance}

The study concluded that of all the efforts that the stakeholders as well as Smart Duka programme organizers have made towards improving informal micro enterprises in the densely populated inormal areas of Nairobi, managerial factors through coaching, inventory management and merchandising have been the most appreciated businesses practice by the micro enterprise 
owners. This is based on the descriptive findings of the study where respondents across the business groups agreed that indeed, the managerial practices has been effective, this factor had the highest composite mean. Correlation established significant positive relationship while regression analysis established insignificant positive relationship between managerial factor and financial performance of the informal micro enterprises involved in the programme of the study. Based on this finding, the study concludes that managerial factor have insignificant positive effect on performance of the businesses. The treated group which were the enterprises that were in business groups had higher ranking mean in comparison to control group under managerial factors although statistically insignificant. The spillover effect of managerial factors was also found to be insignificant. The study therefore concluded that there is insignificant positive spillover effect of managerial factor on financial performance of informal micro businesses in the Smart Duka Project. The differences between the treated and control groups although currently insignificant can be translated into significant differences with time using various interventions given the positive effect of managerial factors on financial performance.

\section{Effect of business group strategic fit factor on financial performance}

Based on the study finding and discussion of the study, the study concluded that strategic fit factors have significant positive effect on the performance of informal micro enterprises in the Smart Duka programme. Further, the study concluded that respondents indeed agreed that they have partnered with other businesses to get better deals on orders and tips on better prices from other businesses. Despite having access to smart phones, the study concluded that majority of the informal micro enterprises still face technology challenges. Most of the micro enterprises both treated and control, do not have technological devices that they can use to track inventory flow/management and daily or monthly sales in the business. Thus, there is need for the programme to expound on the need for group informal micro enterprises to adopt modern technology in their businesses as they enhance transparency, provide effective management practices and enhance capacity of shop owners to track down their sales easily and effectively.

Based on findings, the study concludes that strategic fit factors have significant positive effect on performance of the businesses. The treated group which were the enterprises in business groups had higher ranking mean in comparison to control group under strategic fit factors although statistically insignificant. The spillover effect of managerial factors was also found to be significant. The study therefore concluded that there is significant positive spillover effect of strategic fits factor on financial performance of informal micro businesses in the Smart Duka Project. The differences between the treated and control groups although currently insignificant can be translated into significant differences with time using various interventions given the positive effect of strategic fit factors on financial performance.

\subsection{Recommendations}

The findings of this study suggest that business group factors such as managerial factors, strategic fit factors and financial factors can indeed enhance performance of informal micro retail enterprises involved in the study. However, the most significant of the group the effect of these practices depend on how best micro enterprises apply them towards improving their performances. The study recommends that government need to formulate regulatory and policy structures that can be useful in providing insights into the effect of business group participation of the informal micro enterprises sector. Policies on various business practices especially those related to managerial and strategic fit factors should be formulated as they have positive effects on financial performance of the informal micro enterprises. The study also recommends that practitioners need to design and formulate effective structuring avenues that formal sectors in the economy can find applicable in supporting the group businesses in the informal micro enterprises in the economy.

\section{REFERENCES}

[1] Abor, J., \& Quartey, P. (2010). Issues in SME Development in Ghana and South Africa. 39, 11.

[2] Acevedo, G., \& Tan, H. W. (2010). Impact Evaluation of SME Programs in Latin America and Caribbean. World Bank Policy Research Working Paper.

[3] Asah, F., Fatoki, O. O., \& Rungani, E. (2015). The impact of motivations, personal values and management skills on the performance of SMEs in South Africa. African Journal of Economic and Management Studies, 6(3), 308322. https://doi.org/10.1108/AJEMS-01-2013-0009

[4] Atristain-su, C. (2018). Best Management Practices: SMEs ' Organizational Performance Management Based On Internal Controls in Mexico Best Management Practices: SMEs ' Organizational Performance Management Based On Internal Controls in Mexico. Business International, January 2016. https://doi.org/10.15640/jibe.v4n2a5

[5] Beck, T., \& Cull, R. (2014). SME Finance in Africa. Journal of African Economies, 23(5), 583-613. https://doi.org/10.1093/jae/eju016

[6] Borm, G. F., Fransen, J., \& Lemmens, W. A. J. G. (2007). A simple sample size formula for analysis of covariance in randomized clinical trials. Journal of Clinical Epidemiology, 60(12), 1234-1238. https://doi.org/10.1016/j.jclinepi.2007.02.006

[7] Chatterjee, A., \& Wehrhahn, R. (2015). Insurance for Micro, Small, and Medium-Sized $\quad$ Enterprises. 7(47), 1-8. http://dx.doi.org/10.22617/BRF178794-2

[8] Chatterjee, A., \& Wehrhahn, R. (2017). Insurance for Micro, Small, and Medium-Sized Enterprises [ADB Briefs]. Asian Development Bank. https://doi.org/10.22617/BRF178794-2

[9] Cropanzano, R., \& Mitchell, M. S. (2005). Social Exchange Theory: An Interdisciplinary Review. Journal of Management, 31(6), 874-900. https://doi.org/10.1177/0149206305279602

[10] Hoffmann, W. H., \& Schlosser, R. (2001). Success factors of strategic alliances in small and medium -sized enterprises-An empirical survey. Long Range Planning, 34(3), 357-381. https://doi.org/10.1016/S00246301(01)00041-3

[11] Isaksson, O. H. D., \& Seifert, R. W. (2014). Inventory leanness and the financial performance of firms. Production Planning \& Control, 25(12), 999_ 1014. https://doi.org/10.1080/09537287.2013.797123

[12] Jeppesen, S. (2005). Enhancing competitiveness and securing equitable development: Can small, micro, and medium-sized enterprises (SMEs) do the trick? Development in Practice, 15(3-4), 463-474. https://doi.org/10.1080/09614520500076100

[13] Kadocsa, G., \& Francsovics, A. (2011). Macro and Micro Economic Factors of Small Enterprise Competitiveness. Acta Polytechnica Hungarica, 8(1), 18.

[14] Kamunge, M. S., Njeru, A. K., \& Tirimba, O. I. (2014). Factors Affecting the Performance of Small and Micro Enterprises in Limuru Town Market of Kiambu County, Kenya.

[15] Kodongo, O., \& Kendi, L. G. (2013). Individual lending versus group lending: An evaluation with Kenya's microfinance data. Review of Development Finance, 3(2), 99-108 https://doi.org/10.1016/j.rdf.2013.05.001 
[16] Maina, F. M. (2016). Factors Affecting Growth of Micro and Small Family Business Enterprises: A Case of Nairobi Central Business District. 94.

[17] Mashal, A. (2018). Do Non-Financial Factors Matter for SMEs Performance? "Case from Jordan". Business and Economics Journal, 08(04), 156-167. https://doi.org/10.4172/2151-6219.1000323

[18] Mungai, E. N., \& Ogot, M. M. (2017). Generic Strategies and Firm Performance: An Investigation of Informal Sector Micro-Enterprises in Kenya. https://doi.org/10.5539/ijbm.v12n3p148

[19] Pindado, E., \& Sánchez, M. (2018). Growth-oriented new agricultural ventures: The role of entrepreneurial resources and capabilities under convergence forces. European Review of Agricultural Economics, 1-34 https://doi.org/10.1093/erae/jby039

[20] Sampson Ukpong, M., Acha, I., \& Sampson, M. (2019). A Critique of MicroInsurance Models For Microfinance Banks to Boost SMES in Nigeria. May.

[21] Saunders, M. N. K., Lewis, P., \& Thornhill, A. (2009). Research Methods for Business Students (5th ed). Prentice Hall.

[22] Solly, M. S. (2016). Common causes of small businesses failure in the townships of West Rand district municipality in the Gauteng Province of South Africa. African Journal of Business Management, 6(44), 1099411002. https://doi.org/10.5897/ajbm12.342

[23] The World Bank. (2019). SME Finance. Small and Medium Enterprises (SMEs) Finance. https://www.worldbank.org/en/topic/smefinance

[24] Tinajero, M., \& Lopez-Acevedo, G. (2010). Mexico: Impact Evaluation Of Sme Programs Using Panel Firm Data. The World Bank. https://doi.org/10.1596/1813-9450-5186
[25] User, S. (2016, October 24). 2016 Micro, Small and Medium Enterprises (MSME) Survey Basic Report. Kenya National Bureau of Statistics. https://www.knbs.or.ke/2016-micro-small-and-medium-enterprises-msmesurvey-basic-report/

\section{AUTHORS}

First Author - Caroline Grace Wanjiku, carolyne_gw@yahoo.com; Caroline is a professional with over 20 years of solid results and driven experience in finance, banking, operations, accounting, food science, post-harvest technology, information systems and development. She is a graduate of Strathmore Business School and her research interests are in the area of finance and development.

Second Author - Patricia Chepwogen Chepkwony, kokipatricia@gmail.com, Patricia is a scholar, researcher and mentor in the field of Entrepreneurship. Patricia is a strong player in service to humanity and employs her knowledge, skills and experience in mentoring young people as well as women entrepreneurs. Patricia holds a Doctorate degree in Entrepreneurship, Master of Business administration and Bachelors degree in Business management. 